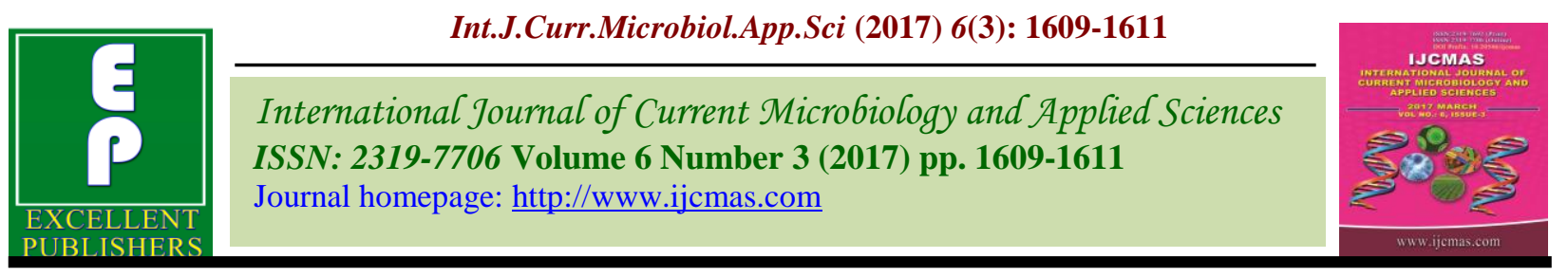

Case Study

https://doi.org/10.20546/ijcmas.2017.603.185

\title{
Tuberculous Peritonitis in Pregnancy: Case Report
}

\author{
Y. Rai*, A. Mahor, R. Kaur, G. Dhaka and A. Shaweny \\ Department of Microbiology, Lady Hardinge Medical College, India \\ *Corresponding author
}

\begin{tabular}{|c|c|}
\hline & A B S T R A C T \\
\hline $\begin{array}{l}\text { Ke y w o r d s } \\
\text { Tuberculous } \\
\text { peritonitis, } \\
\text { Pregnancy, Ascitic } \\
\text { fluid, LJ media. }\end{array}$ & \multirow{3}{*}{$\begin{array}{l}\text { The incidence of tuberculosis in pregnancy is low; moreover, peritoneal } \\
\text { tuberculosis (PT) in pregnancy is uncommon as infertility is the commonest } \\
\text { sign in case Tuberculosis involves the genitals and/or peritoneum1. The } \\
\text { clinical manifestations of tuberculous peritonitis progress insidiously. The } \\
\text { present study reported here a case of tuberculous peritonitis in pregnancy } \\
\text { presenting with ascites. Extrapulmonary tuberculosis (EPTB) has become } \\
\text { an important clinical problem in past few years. Pregnancy being an } \\
\text { immune compromised state increases the risk for getting tubercular } \\
\text { infection and reactivation of primary pulmonary tuberculosis infection in } \\
\text { women. }\end{array}$} \\
\hline Article Info & \\
\hline $\begin{array}{l}\text { Accepted: } \\
\text { 22 February } 2017 \\
\text { Available Online: } \\
10 \text { March } 2017\end{array}$ & \\
\hline
\end{tabular}

\section{Introduction}

The incidence of tuberculosis in pregnancy is low; moreover, peritoneal tuberculosis (PT) in pregnancy is uncommon as infertility is the commonest sign in case Tuberculosis involves the genitals and/or peritoneum (Lee et al., 2005). The clinical manifestations of tuberculous peritonitis progress insidiously. Fever, chills, weight loss and abdominal pain are common complaints. Though, ascites is present in almost all patients, bacteriologic examination of the ascitic fluid is not always diagnostic. Acid-fast smears are rarely positive in tuberculous peritonitis, and conventional cultures yield the pathogen in only $25 \%$ of cases (Sakorafas et al., 2009). We report here a case of tuberculous peritonitis in pregnancy presenting with ascites.

\section{Case report}

A 26 years old female, primigravida with 26wks pregnancy presented with pain and distention of abdomen since 15 days, low grade on and off fever since 2 months, associated with weight loss, anorexia and bilateral pedal oedema since 1month. On examination, her pulse rate was $86 / \mathrm{min}$, BP $110 / 70 \mathrm{~mm} \mathrm{Hg}$, Chest was bilaterally clear, Abdomen was grossly distended with fluid thrill and shifting dullness present. 
Routine laboratory examination revealed Hb6.1 gm/dL and TLC 4500/micro litre. Preterm labor pain started and she delivered a baby girl of $864 \mathrm{gm}$ through normal vaginal delivery. The new born baby was shifted to neonatal ICU. Blood culture and urine culture with antimicrobial sensitivities revealed no growth. Urine routine microscopy revealed RBCs 10-13/hpf, pus cells 4-7 /hpf, few epithelial cells, cast/crystals-nil. Routine biochemistry revealed SGPT-278 IU/ml, SGOT-33 IU/ml, alkaline phosphatase-7 $\mathrm{IU} / \mathrm{ml}$. USG abdomen revealed fatty liver, septal collection in lower abdomen, CECT abdomen revealed iliocecal junction thickening with loculated ascites, abdominal nodes and omental thickening. Patient was put on antitubercular therapy. Abdominal drain was inserted under GA, $600 \mathrm{ml}$ of seropurulent fluid drained out and sent for cytology, biochemistry and AFB staining and mycobacterium tubercular culture to microbiology laboratory. Zeihl-Neelsen staining of ascitic fluid revealed no acid fast bacilli. Ascitic fluid cultured on LJ media at $37^{\circ} \mathrm{c}$, after 3 wks revealed rough, tuff and buff colonies on LJ media. ZN staining from colonies revealed acid fast bacilli. On follow up the patient was gradually improved.

Fig.1 LJ medium showing rough, tuff and buff colonies

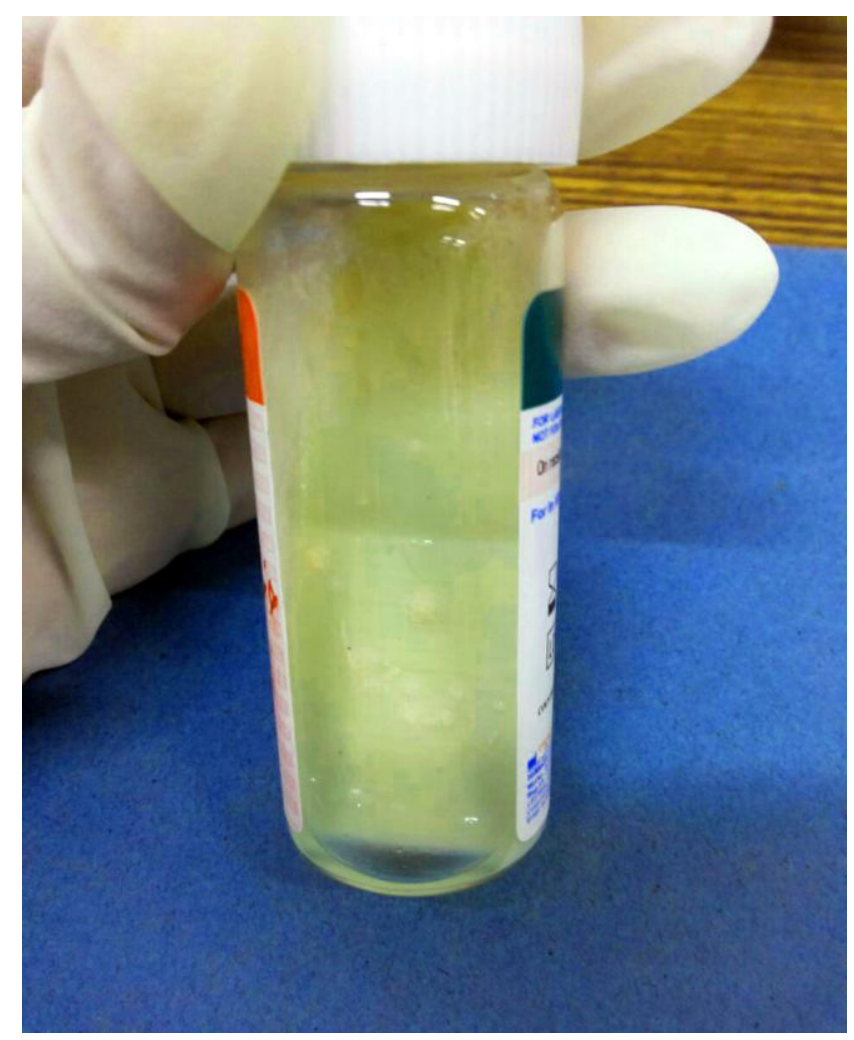

\section{Results and Discussion}

Extrapulmonary tuberculosis (EPTB) has become an important clinical problem in past few years. Pregnancy being an immune compromised state increases the risk for getting tubercular infection and reactivation of primary pulmonary tuberculosis infection in women. The diagnosis is often missed or late in pregnancy due to the vague and nonspecific features of extrapulmonary TB. In developing countries like India where the 
prevalence rate of tuberculosis is high the investigation protocols should include evaluation of tuberculosis in every antenatal case. There is limited data on extrapulmonary tuberculosis during pregnancy and postpartum period. Studies have shown that biological changes in pregnancy and postpartum period may affect tuberculosis infection (Zenner et al., 2012). Microscopic examination of sputum or other specimen, for acid-fast bacilli remains the cornerstone of laboratory diagnosis of tuberculosis in pregnancy. Three samples of sputum should be submitted for smear, culture, and drug-susceptibility testing (Loto et al., 2012). The traditional culture on Lowenstein-Jensen's medium may take 4 to 6 weeks to obtain a result. This may, however, still be useful in cases of diagnostic doubts and management of suspected drug-resistant tuberculosis (World Health Organization, 2009).

Bacteriologic examination of the biopsy specimen should be performed, because this could be positive for tuberculosis when histological examination is negative. This examination includes the identification of acid-fast bacilli (Ziehl-Neelsen staining positive), positive culture for Mycobacterium tuberculosis and positive PCR for $\mathrm{M}$ tuberculosis complex (Piura et al., 2003). Early diagnosis and treatment of peritoneal tuberculosis in pregnancy are important in minimising adverse obstetrical and neonatal effects (Dalamón et al., 2008; Schram et al., 2005).

\section{References}

Dalamón, R.S., Cantelli, S.N., Jaroslavsky, D., Bruno, M., Debuh, M.A., Falk, J. 2008. Congenital tuberculosis. Infrequent presentation of a common disease. Arch. Argent Pediatr., 106(2): 147-50.

Lee, G.S., Kim, S.J., Park, I.Y., Shin, J.C., Kim, S.P. 2005. Tuberculous peritonitis in pregnancy. J. Obstet. Gynaecol. Res., 31(5): 436-8.

Loto, O.M., Awowole, I. 2012. Tuberculosis in pregnancy: a review. J. Pregnancy, 379271.

Piura, B., Rabinovich, A., Leron, E., Yanai Inbar, I., Mazor, M. 2003. Peritoneal tuberculosis, an uncommon disease that may deceive the gynecologist. Eur. J. Obstet. Gynecol. Reprod. Biol., 110: 230-234.

Sakorafas, G.H., Ntavatzikos, A., Konstantiadou, I., Karamitopoulou, E., Kavatha, D., Peros, G. 2009. Peritoneal tuberculosis in pregnancy mimicking advanced ovarian cancer: a plea to avoid hasty, radical and irreversible surgical decisions. Int. J. Infect. Dis., 13(5): e270-2.

Schram, A.J., Holm, J.P., van Altena, R. 2005. Two pregnant immigrant women with tuberculous peritonitis. Ned Tijdschr Geneeskd., 149(35): 1958-61.

World Health Organization. 2009. Stop TB Partnership: Pathways to Better Diagnostics for Tuberculosis: A Blueprint for Development of TB Diagnostics. Geneva, Switzerland: World Health Organization.

Zenner, D., Knujshaar, M.E., Andrew, N., Abubakar, I. 2012. Risk of tuberculosis in pregnancy: a national primary care based cohort and self-controlled case series study. Am. J. Respir. Crit. Care Med., 185: 779784.

\section{How to cite this article:}

Rai, Y., A. Mahor, R. Kaur, G. Dhaka and Shaweny, A. 2017. Tuberculous Peritonitis in Pregnancy: Case Report. Int.J.Curr.Microbiol.App.Sci. 6(3): 1609-1611.

doi: https://doi.org/10.20546/ijcmas.2017.603.185 